\section{THE ETIOLOGY OF DEMENTIA PARALYTICA. ${ }^{1}$}

By W. FORD ROBERTSON, M.D. EDIN., PATHOLOGIST TO THE SCOTTISH ASYUUMS.

No apology should be required for bringing before a health congress any new observations bearing upon this question. Dementia paralytica and the closely allied disease tabes dorsalis, notwithstanding the vast amount of research that has been expended upon them, are still unconquered, and continue from year to year to exact their heavy toll of suffering, disablement, and death in every civilised country.

At the present day it is almost universally held that dementia paralytica is a manifestation of syphilis. I do not wish on this occasion to raise any discussion on the question of the validity of the evidence upon which this conclusion is founded. I shall merely say that in my judgment a satisfactory case has been made out for no more than thisnamely, that previous infection by the treponema pallidum strongly predisposes to the development of dementia paralytica and tabes dorsalis. My purpose is to bring bricfly before the section some of the evidence that can be adduced in favour of the view that general paralysis and tabes dorsalis are both dependent upon an infection of quite a different nature from that which produces syphilis.

For the past ten years, in so far as time and opportunity have permitted, I have made a special study of the question of the etiology of dementia paralytica and tabes dorsalis. ${ }^{2}$ Qn the ground of the first bacteriological observations it was suggested that dementia paralytica might be due to a chronic infection by an attenuated form of the Klebs-Löffler bacillus. It was, however, soon found that the organism to which importance was attached was essentially different from this bacillus; it had different biochemical reactions, and it was often virulent to mice, never to guinea-pigs. Still later, the impossibility of proving that there is in dementia paralytica a constant infection of the brain by a bacillus of the diphtheroid group made it clear that the hypothesis of a simple bacillary infection of this kind did not offer a complete explanation of the morbid phenomena. Nevertheless, facts had been ascertained that made it impossible for me to abandon the view that this bacillus, which has for convenience been referred to as the bacillus paralyticans, had an important etiological relationship both to dementia paralytica and to tabes dorsalis, and the work was therefore continued. Gradually the evidence has accumulated, until it is no longer a question of whether the bacillus paralyticans produces paresis, but only one of how it acts. It certainly does not operate in the manner of an ordinary bacterium. Before giving a brief summary of this evidence, I should like to say that, in the course of these investigations, other evidence has accumulated skowing that the diphtheroid group of bacilli is a much larger and more important one than it is commonly supposed to be. Apart from the KlebsIöffler bacillus, an altogether exceptional and very misleading member of the group, there are certainly several different species that are agents in the causation of very common diseases. 'The most important of these species will rarely grow upon the ordinary agar media, and they may even refuse to grow upon a serum medium. What they require is unaltered hæmoglobin.

I. shall now briefly summarise the evidence showing a connexion between infection by a bacillus of the diphtheroid group and dementia paralytica, with which must be associated tabes dorsalis. If hæmoglobin agar is used as the culture medium, it can be shown that the bacillus paralyticans is constantly present in the genito-urinary tract and the nasal mucosa of the general paralytic. In tabes dorsalis there is always in the early stages an infection of the genito-urinary tract by a similar micro-organism; in the later stages this bacillus may be entirely displaced by a coliform one. The nasal infection in geveral paralysis can be traced along the lymphatics, througli the base of the skull,

1 A paper read in the Section of Pathology and Bacteriology at the annual meeting of the Royal Institute of Public Health, Berlin, July 24 th-28th.

2 'See Review of Neurology and Psychiatry, May and July, 1903 May, 1905; and February, March, and April, 1906 ; Journal of Menta Science, July, 1907; October, 1907; Jannary. 1909; October, 1909 Octob́er, 1910; THE LANCET, Nor. 14th, 1908. to the intracranial lymphatic system, and a culture of the bacillus can be obtained from the ccrebro-spinal fluid in a considerable, though certainly not a very large proportion of cases. Intraspinal injection of living cultures of the bacillus paralyticans in rabbits has produced lesions in the cord identical with those that occur in the brain of the general paralytic. In the course of these experiments it was found that the cerebro-spinal fluid, withdrawn a few days after the injection of living bacilli, yielded no growth. Nevertheless, the morbid process continned, and in several instances resulted in complete paralysis of the hind limbs and death of the animal within a few weeks or months. A few of the animals were only slightly affected, but several of these have, after a latent period of from 18 months to two years, developed well-marked paresis. As inflammatory changes in the cord and consequent paralysis can be produced by the intraspinal injection of almost any micro-organism or toxin, and as plasma cells are not special to general paralysis, it became obvious to me that the question of the relationship of this bacillus to general paralysis could not be settled by this method of experiment. I therefore abandoned it and adopted another--namely, that of the infection of the genito-urinary tract. Some rabbits are specially resistant to such local infection by the bacillus paralyticans, but the rule has been that the animals have become ataxic and paretic after some months. Out of 16 rabbits so infected, ten have developer? paresis, and two of the ten have succumbed to their illness. Further, it has been proved that the disease has the characters of a contagious vencreal one. I have three male rabbits that have not been injected, but which nevertheless show well-marked ataxia and paresis of the hind limbs; ther have merely been placed beside females the genital tract of which had been infected with the bacillus.

It has, as yet, been impossible for me, on account of official duties, to make a complete histological examination of the tissues of the two rabbits that have died as a result of infection of the genital tract with this bacillus. I can, howerer, demonstrate some of the chicf morbid changes that they present. 'The first rabbit (Experiment 36) was a male that had received several intra-urethral injections of the bacillus paralyticans. After some weeks it gradually became dull and stupid, and slow and awkward in its movements. It was, however, exceptional in respect of the fact that it never developed a severe degree of paresis and ataxia. The higher cerebral functions seemed to be chiefly affected. When placed on the ground the animal would generally remain motionless, with eyes half closed, and would refuse to move either for boot or dog. It became thin, and died two years and three months after the commencement of the experiment. The abdominal and thoracic organs were not affected by any gross disease. Microscopical examination of the brain and spinal cord shows that any morbid alterations that can be detected in the meninges, vessels, and neuroglia are very slight, and that the characteristic picture of general paralysis is not reproduced. The cortical and spinal nerve cells present, however, very severe and widespread chronic changes. These consist in chromatolysis with a more or less fine racuolation of the cytovlasm; in many instances the process can be seen to be going on to degeneration of the nucleus and disintegration of the cell. However it may be explained, the fact is that the morbid changes in this rabbit, as well as the features presented by the animal during life, resemble to some extent those of dementia præoox and not those of general paralysis.

The second rabbit (Experiment 38) was a female which was given intravaginal injections of the bacillus paralyticans. Nineteen months after the experiment was begun it was noticed that the animal had become ataxic and paretic in the hind limbs, which were at times simply dragged along as the rabbit progressed by means of its forelegs. There were also distinct signs of dementia. The animal gradually became completely paralysed in its hindquarters. It was killed with chloroform about six weeks after the paresis was first observed. 'The pelvic organs were found to be intensely congested. The lumbar vertebræ were inflamed and softened, and there was some whitish deposit between the bone and the dura. Similar but less extensive softening of the vertebra has been observed in some of the rabbits of the previous series that were injected intraspinally with cultures of the bacillus paralyticans. Microscopical examination of the lumbar cord shows dense infiltration of the pia 
with lymphocytes and plasma cells, especially over the posterior part of the cord. (Fig. 1.) There are very wellmarked hypertrophy and proliferation of the neuroglia throughout a broad zone of the white matter below the pia. Many of the vessels within the substance of the cord show periarteritis. A consiclerable proportion of the cell-clements in

FIG. 1.

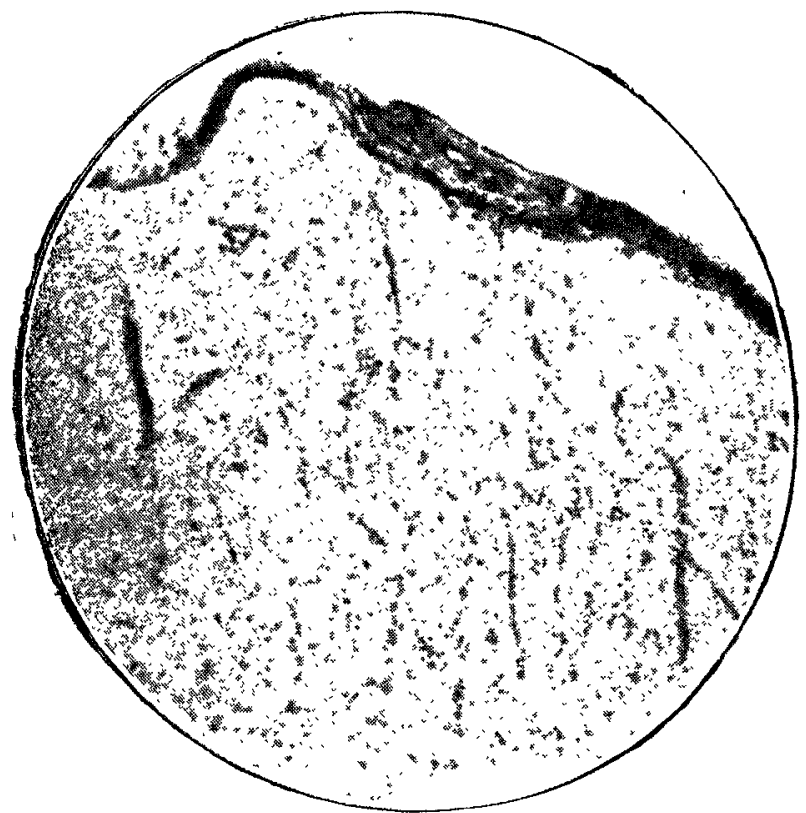

Section of spinal cord of rabbit. Experinental infection of genital tract with bacillus paralyticans. Shows cellular infiltration of pia, hypertrophy of neuroglia, and periarteritis. Methylene blue. $\times 50$.

the walls of these ressels are plasma cells. (Fig. 2.) In the grey matter the morbic changes are comparatively slight; a small proportion of the nerve cells show recent degenerative changes. In this rabbit the infection of the genital tract with the bacillus paralyticans has been followed by the development of morbid tissue-changes in the lumbar spinal cord that resemble those that occur in the brain in cases of

Fig. 2.

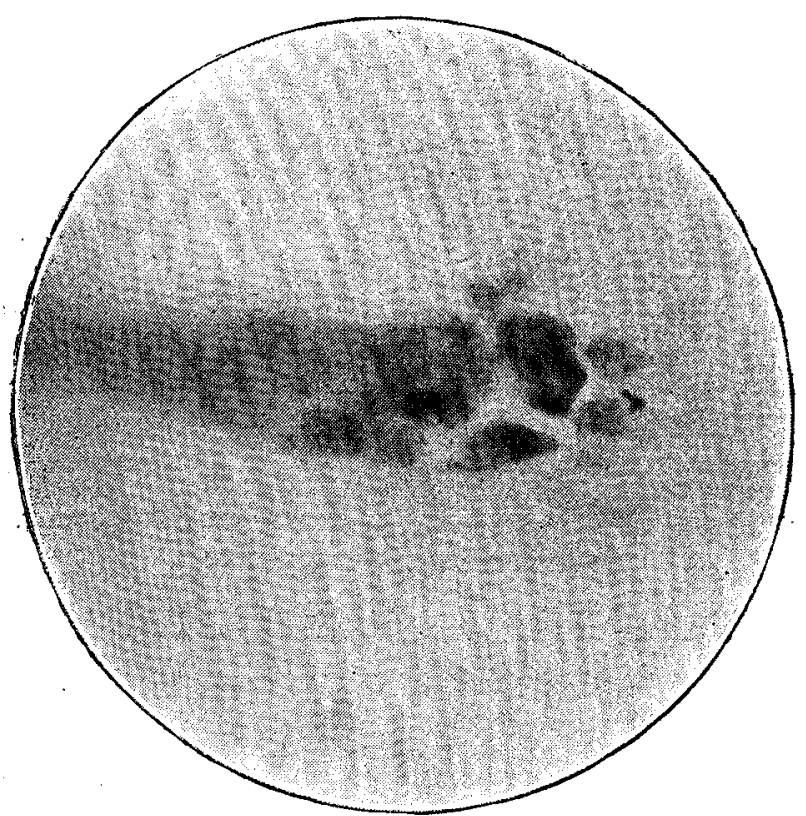

Section of spinal cord of rabbit. Experimental infection of genital tract with bacillus paralyticans. Arteriole showing plasma cells in its wall. Methylene blue. $\times 800$.

dementia paralytica. Both of two male rabbits that were placed from time to time beside this female are now paretic. Much additional evidence with which I cannot at present deal has been collected by others and by myself, showing that these bacilli are capable of exercising a powerful neurotoxic action, that they may produce lesions identical with those that occur in dementia paralytica, and that they bave an intimate connexion with this disease in the human subject.

Now this bacillus certainly does not grow on in the nervous tissue as a diphtheroid bacillus, yet the morbid process continues and leads to death. There are at least two possibilities regarding its mode of action. First, it may by its toxins initiate changes in the tissues which, when once started, are in their very nature progressive. This view was favoured at one time, but I think it must be put aside as inadequate. Secondly, the bacillus may, perhaps under anaerobic conditions, develop into something else, not readily recoonisable, and this further stage may be the essential pathogenic agent. The more fully the facts have been elucidated, the more strongly have they indicated that this is the true explanation. In short, these diphtheroid bacilli are not bacteria at all, but phases in the life cycle of a protozoon, and this applies not merely to the diphtheroid bacilli that are capable of producing paresis, but to the whole group. There is cultural evidence in support of this view, but I do not wish to bring it forward at present. I wish merely to demonstrate by means of lantern slides and microscopical preparations some of the evidence that can be adduced in favour of the existence of an active infective agent in the brain of the general paralytic.

There is a special feature of the brain in cases of dementia paralytica that I have had under observation for the last 15 years; its meaning was inexplicable until other facts suggested that the bacillus paralyticans is only a stage in a life-cycle. This feature consists in an accumulation of very minute bodies, sometimes rod-shaped, but generally quite irregular in form, in the lymphatic spaces around the vessels and nerve cells of the cerebral cortex. These bodies are quite invisible in sections stained by the ordinary methods they are clearly revealed, so far as I have been able to ascertain, only by the palladium methyl violet method. I have now observed them in a very large number of brains, but only in those of general paralytics. They are very minute, being as a rule much smaller than a staphylococcus, though larger forms also occur. When closely examined they are seen to consist of a deeply-stained central particle and a comparatively very pale surrounding portion. They have, in short, the morphological characters of amœbulæ.

Another body which in my experience is special to the brain of the general paralytic, and which is probably of a parasitic nature, is a very minute delicate rod which is revealed also by the palladium methyl violet method. Though it occurs throughout the cerebral tissues, it is most easily recognised within the cytoplasm of the nerve cell where there are no neuroglia fibres and axis-cylinders to complicate the picture. Two or three such rods may commonly be seen in one cell. They are perfectly smooth, and therefore differ morphologically from the granular diphtheroid bacilli. They have also been found in the cerebro-spinal fluid. Neither these amobula bodies nor these minute rods are normal constituents of the brain, and their development as the result of any pathological process cannot be traced. They have characters that are those of micro-organisms, and I venture to maintain that they are of this nature.

In this connexion I wish also to direct attention to the occurrence in the brain of what may be termed cyanide. resisting bodies. If a piece of the cerebral cortex from a case of dementia paralytica is prepared by my ammonio-silver process and the sections are decolourised by means of potassium cyanide, either after or before toning with gold chloride, there may usually be observed under the micro. scope more or less numerous small objects that have retained the gold or silver deposit. In this sense they are cyanideresisting bodies. Now the view that these bodies are simply accidental metallic deposits can be shown to be erroneous, as regards at least many of them, for as the gold or silver is dissolved away, a pale object is left which can be stained by certain dyes. Nevertheless, the more the question of the nature of these cyanide-resisting bodies has been investigated, the more complex and difficult has it appeared. It is certain that the cyanide-resisting character is not distinctive of any one structure; it is shared by many different elements-by some that are degenerative, and by others, as, for example, bacteria, that are micro-organismal. Consequently, bodies having this character are common in various morbid tissues. There are, however, several reasons for which it is important that a thorough investigation should be made of the bodies of this kind that occur in the brain of the general paralytic. They are commonly present locally in very great numbers; their origin has not been 
traced; and many of them have, to all appearance, a nucleus and cytoplasm. They are usually rounded objects of a black or reddish appearance from 0.5 to about $4 \mu$ in diameter; they occur not only in the intercellular spaces, but also in the cytoplasm of the nerve cells. My own observations do not as yet warrant my offering any definite opinion as to their significance.

Lastly, in summarising the evidence in support of this view of the etiology of dementia paralytica and tabes dorsalis, I would not omit that which has been obtained from the treatment of cases. In view of the results of the bacteriological and experimental investigations, it has seemed to myself and others legitimate to endeavour to cure these diseases by means of vaccines and antiserum. In tabes dorsalis, especially in early cases, the results of vaccine treatment have in many instances been highly satisfactory. The gait has become steadier, pain has been relieved, the patient's general health has improved, and he has been able to resume work. It has only been in very advanced cases, and in the thin, neurasthenic type of patient, that the results have been in the least discouraging. In general paralysis, on the other hand, the most that I can claim is that in a few cases there has apparently been some retardation of the rate of progress of the malady.

The antiserum which I have employed has been prepared in the sheep. Given by hypodermic injection, this antiserum has produced at most only slight and very temporary beneficial effects. Given by intraspinal injection, it has, however, yielded some very striking results. In the first series of observations of this kind, carried out for the most part in general paralytics in an advanced stage of their disease, there was in most instances no very obvious benefit. In one case, however, the injections were followed by very remarkable improvement. The patient was a woman who for over a year had been in a stuporose condition, though not bedridden. The treatment was quickly followed by complete disappearance of the stupor, so that the patient was able to converse freely and rationally, to work and to read newspapers and books. This improvement was maintained for over six months, when she began to relapse. Some time later, when the patient was bedridden, I was asked to repeat the injections; on this occasion they had no beneficial effect. I have treated one case of tabes dorsalis by intraspinal injection of antiserum. The case was that of a young man in whom the disease was progressing rapidly. Following a series of three intraspinal injections of antiserum, there has been a complete arrest of the further progress of the malady, and the patient after nearly a year remains in this satisfactory condition. In the course of these observations it was perceived that a sharp rise of temperature followed some of the injections, but not all of them, and it appeared that such a rise of temperature rarely, if ever, occurred unless the serum was quite fresh. That there is actually some special potency in the fresh antiserum which is associated with this thermogenic action seems to have been established by a new series of observations kindly carried out for me during this summer by physicians in various asylums. Whether this constant rise of temperature upon intraspinal injection of fresh antiserum is characteristic of dementia paralytica I cannot say, for it has been impossible to have similar injections made in control cases. In several of these cases of dementià paralytica recently treated with fresh antiserum very marked improvement has already been reported.

\section{The Palladium Methyl Violet Method.}

The reagents required are saturated solution of palladiun chloride in 1 per cent. citric acid in water, 1 per cent. solution of methyl violet iodide $5 \mathrm{~B}$, saturated solution of iodine in 2.5 per cent. potassium benzole, benzole oil, equal parts of pure anhydrous aniline oil and 5 per cent. formalin in 3 per cent. salt solution (and preserved in the same fluid or in alcohol), or for 24 hours in Heidenhain's sublimate solution, with subsequent removal of the mercury by means of iodine in the asual way. Cut thin sections by the dextrin freezing method. Place the sections in the palladium solution, diluted with an equal quantity of 1 per cent. citric acid until they assume a pale straw colour (one half to 24 hours). Wash them in three changes of water and then place them for from io to 20 minutes in the methyl violet stain. Wash the sections shortly in water and transfer them to the iodine solution, in which they should remain for from 10 minutes to 1 hour. Next transfer the sections to a bowl of water. In this they may be left for an hour or longer without suffering harm. Steel needles must not be used in these operations. Take a section up from the water upon a perfectly clean slide. Carefully remove water from around it by means of a towel. Next lay the slide upon the table and with a piece of smooth blotting or filter paper (folded double) blot the section in the wards, without allowing it to dry completely in air, pour over the section some drops of origanum oil. Renew this after a few seconds and
then place the slide upon the heater (described below) where it must remain at a temperature of about $60^{\circ} \mathrm{C}$. until completely dehydrated. If the origanum oil tends to evaporate off the section add more by means of a pipette. When dehyclration is complete the previously black and opaque tissue assumes a dark blue and faintly translucent appearance. Generally from 15 to 20 minutes are required. When the section seems dehydrated remove the slicle from the heater, allow it to cool, and then pour off the origanum oil. Decolourise with anilinebenzole. Renew this two or three times. Avoid breathing on the slide as the smallest trace of moisture in the aniline-benzole will cause complete decolourisation of the section. When the dyo ceases to come away wash the section in several changes of pure benzole and mount ins balsam in benzole. It is essential that the section should be com. pletely rehydrated on the heater. Any spot in which moisture has been allowed to rumain will be decolourised by the aniline-benzole. A heating apparatus of a very simple form is sufficient for the purposes
of this method. I use a small spirit lamp placed below a tripod stand, of this method. I use a small spirit lamp placed below a tripod stand,
on the top of which there is a thin metal plate, and upon this again two on the top of which there is a thin metal plate, and upon this again two
small iron bars laid parallel to each other and at such a distance as just to allow the two ends of a microscopic slide to rest upon them. By such to allow the two ends of a microscopic slide to rest upon them. By such an arrangement heat is transmitted only by the two ends of the slide
and the origanum oil is driven to the centre. Tissues that have been and the origanum oil is driven to the centre. Tissues that have been
in alcohol or in formalin for over two years do not, as a rule, stain in alcohol or in formalin for over two years do not, as a rule, stains
deeply enough, and must then be regarded as unsuitalle for the application of this methorl.

\section{Ammonio-silver Method.}

1. Fix slices of tissue, 8 inch thick, in Heidenhain's sublimatc solution for 24 hours.

2. Remove the sublimate by putting the pieces in 80 per cent. alcohol, coloured sherry colour with iodine. Renew this fluid as it becomes decolourised, and use weaker iodine solutions towards the end. Seven to ten days are generally required.

3. Wash out iodine in 80 per cent. alcohol, and keep pieces in 80 per cent. alcohol till required.

4. Before silvering, wash out the alcohol in water and place the piece of tissue in 5 per cent. formalin in distilled water for 24 hours. Formalin fixed tissues may also be used.

5. Wash out formalin in several changes of water for three and a hall hours or longer. Rinse piece well a short time before putting into the silver solution.

6. The silver solution is made by adding to a 5 per cent. solution of silver nitrate in distilled water 5 per cent. ammonia in distilled water, till the precipitate first formed redissolves, and then adding silver nitrate solution till the cloud formed has become quite dense. (The nitrate solution till the cloud formed has become quite dense. (The
bottle to be used must not have contained formalin.) Five c.c. of this bottle to be used must not have contained formalin.) Five c.c. of this
solution are ample for a piece of tissue the size of a shilling. Too large solution are ample for a piece of tissuc the size of a shilling. Too large
a quantity tends to make the tissue friable when cut. The bottle containing the solution and tissue is corked and incubated at $37^{\circ} \mathrm{C}$. for seven days. If the fluid has been rightly made up, it should after a few hours' incubation be clear, or have a slight violet tinge, and show a black silver deposit. If the sides of the bottle become silvered, another nust be taken and fresh solution prepared.

7. The tissue is next washer in water, to which enough ammonia has been added to be distinctly perceptible to the smell. The surface deposit of silver must be rubbed off gently with the fingers. The water should be changed several times, and the washing should be continued for eight hours or longer. Thereafter, the tissue is left overnight ir dextrin solution, to which enough ammonia has been added to turn the reaction markedly alkaline. Prolonged action of the dextrin solution must be avoided, as it interferes with the subsequent toning. 8. Thin sections are cut with a freezing microtome, and transferred to 8. Thin sections are cut with a freezing microtome, and transferred to
a bowl of ammonia water. They receive a second wash in ammonia and a bowl of ammonia water. They receive a second wash in ammonia and water, and are then transferred to water acidulate
After a few minutes they are placed in tap water.

After a few minutes they are placed in tap water.
9. Place sections over-night in a toning bath composed of equal 9. Place sections over-night in a toning bath composed of equal
quantities of 1 per cent. gold chloride in distilled water and 1 per cent sodium tungstate (tissolved in boiling distilled water).

10. Wash sections well in water.

11. Decolourire sections by placing them in 1 per cent. potassium cyanide solution.

12. Wash sections well in water.

13. Dehydrate with absolute alcohol, clear in origanum oil, and monnt in benzole-balsam.

After having been decolourised with cyanide, the sections may be counterstained. The most suitable stain is Ehrlich's hrmatoxylin. It The cyanicle bath mav be used before instead of after gold-toning.

\section{AMPUTATION IN INFANTILE PARALYSIS}

By EDRED M. CORNER, M.C. CANTAB., F.R.C.S. ENG.

CONSULIING SLRGHON TO S'T. NICHOLAS'S HUME; SURGEON AND LECIURFR TO \$T. 'THOMAS'S IIOSPITAL AND TO THE CHIDREA'A HOSPITAL, GREA'I ORMOYD-S'TREET' AND

C. E. BASHALL, M.R.C.S. ENG., L.R.C.P. LoND:; MEDICAL OFFICER TO S'I'. NICHOLAS'S HOME.

THE great tendency of the progress of modern surgery is; and has been, towards conservatism, no part which can be saved being sacrificed. Even an organ which has so small a function as the appendix has given rise to the cry that having a use it should not be sacrificed. Considering this general tendency, it is very unusual for a modern surgeon to be able to record the results of a series of amputations done for a condition which, had it been attacked by a surgeon before, would probably never have come to amputation.

Upon our taking professional charge of the St. Nicholas's Home for Waifs and Strays at Pyrford, Surrey, we found certain infantile paralytics upon whon, owing to their 